\title{
MRI 定域波谱及其抑制水峰新方法的应用*
}

\author{
丁广良李丽云孟庆安 $* *$ 叶朝辉 \\ (中国科学院武汉物理研究所, 波谱与原子分子物理国家重点实验室, 武汉 430071)
}

\section{关键词磁共振成象 定域波谱 水峰抑制 特形脉冲 受激回波}

磁共振成象 (Magnetic resonance imaging, MRI) 在过去 20 年里取得了巨大进展 ${ }^{[1]}$, 在医 学、生物、材料科学等领域有着广泛的应用 ${ }^{[2]}$. 随着 MRI 方法的日益发展, 其应用的深度和广 度必将会进二步扩大 ${ }^{[3]}$.

用 MRI 方法获得空间定域和空间分辨, 进一步获取感兴趣区域 (Volume of interest, VOI) 的波谱, 即磁共振波谱 (Magnetic resonance spectroscopy, MRS) 方法, 是目前 MRI 非 常活跃的领域. MRS 方法能够无损害地在整个活体内 (in vivo) 获得不同区域内各种化合物 的高分辨波谱, 并由此得到生物组织的新陈代谢信息, 特别在人脑功能的研究中有着巨大的 潜力 ${ }^{[4]}$, 在医学诊断中也会成为重要手段.

由于生物组织中水占有很大比重, 而其它重要的具有生物活性的化合物的量相对很少, 因 此 MRS 中水峰抑制问题就显得很突出.

\section{1 实验方法}

空间定域的方法很多, 如 SPACE ${ }^{[1]}$ 、ISIS ${ }^{[1]}$ 、DIGGER ${ }^{[1]}$ 等。本文实验采用受激回波采集模 式 (Stimulated echo acquisition mode, STEAM) 进行 VOI 的选择 ${ }^{[5]}$, 脉冲序列见图 1 .

实验过程首先用通常的 MRI 方法选取 $Z$ 方向上的切片, 作 XY 平面象, 然后选择平面上 的位置. 为了保证所选区域的正确性, 在获取定域谱前还要做定域象. 图 2(a) 是用自旋回波 法所成 XY 平面象, 图 2(b) 是用 STEAM 法成的定域象. 实验在 BRUKER MSL-400 微成象 系统上完成, 探头用 $\Phi 10 \mathrm{~mm}$, 模型样品 (phantom) 为 $\Phi 10 \mathrm{~mm}$ 样品管内装 $4 \%$ 乙醇水溶液, VOI 为 $2 \times 2 \times 2 \mathrm{~mm}^{3}$, 其中心沿 $X$ 轴偏离管中心 $2 \mathrm{~mm}$.

水峰抑制方法也有多种, 如多脉冲、水门裁剪激发、化学位移选择饱和等. 本文实验利用 本实验室的近期研究结果 ${ }^{1}$, 其特点是先在 $+X$ 相位用连续波照射水峰, 紧接着相移 $90^{\circ}$ 在 $+Y$ 相位进行较短时间的照射, 以消除自旋锁定 (Spin locking) 效应. 比较实验结果后, 我们用 GAUSS 形状的特形脉冲取代连续波照射, 在空间定域前对水峰实行预饱和.

1994-12-21 收稿, 1995-06-26 收修改稿

*国家自然科学基金资助项目

**永久通讯地址: 中国科学院物理研究所, 北京 100080

1) 该文送审期间, 此结果已发表, 见文献[6] 


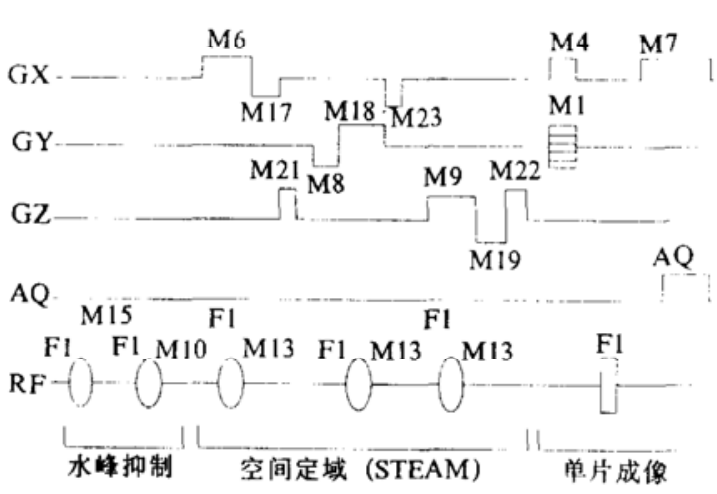

图 1 实验脉冲序列

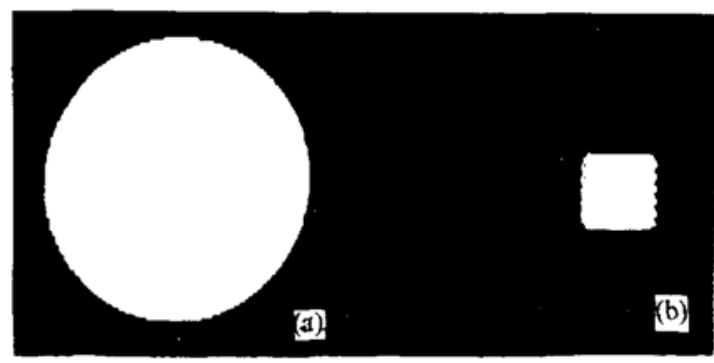

图 2 模型样品的单片象 (a) XY 平面象, (b) 定域象

\section{2 实验结果}

图 3 给出了实验的部分谱图. (a) 图是非定域的 ID 谱, 采样 1 次, 故发射峰没有被消

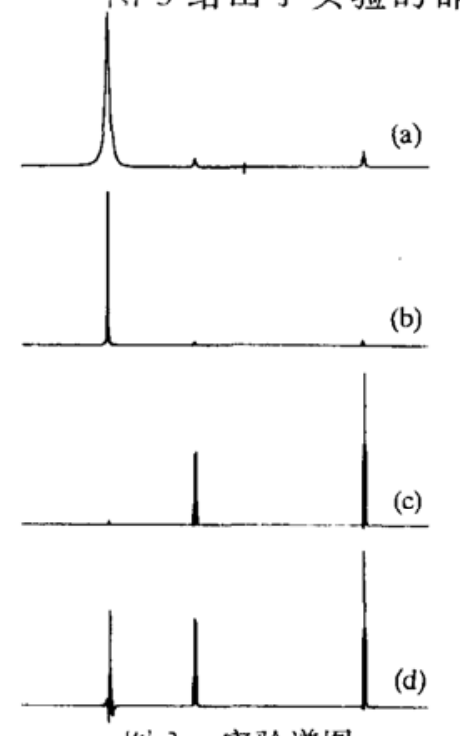

约 3 实验谱图

(a)非定域一维谱, (b) 定域谱, (c) 抑制水峰定域谱, (d) 梯度散相抑 水峰定域谱 除, 水峰线宽有 $17 \mathrm{~Hz}$.(b) 图是定域波谱, 由于小区域内磁场均匀 性得以改善, 分辨提高, 线宽窄化为 $1.9 \mathrm{~Hz}$. 采样 16 次, 为一相位 循环, 发射峰被消除. (c) 图是水峰抑制的定域波谱, 所用 GAUSS 脉冲在 $0.1 \%$ 处截断, 数据点为 $2 \mathrm{~K},+\mathrm{X}$ 相位脉冲长度是 $10 \mathrm{~s},+\mathrm{Y}$ 相位脉冲时间为 $1 \mathrm{~s}$. 脉冲幅度 4.000 , 采样 16 次. (d) 图是用 $90^{\circ}$ 化学位移选择脉冲对水峰进行激发, 接着用梯度脉冲散相, 这个 过程分别在 $X 、 Y 、 Z$ 三个方向进行. 梯度作用时间为 $1 \mathrm{~ms}$, 梯度 强度已达 $0.4 \mathrm{~T} / \mathrm{m}$, 接近微成象系统的极限, 但很明显, 它的抑制 水峰效果不如 (c) 图好.

\section{3 讨论}

我们在用 MRI 方法获得 MRS 的基础上, 采用 GAUSS 特形 脉冲在空间定域前对水峰进行正交相位上时间一长一短的预饱 和照射, 获得了选择性和水峰抑制效果都比较好的空间定域谱.

表 1 给出了与图 3(b)、(c) 相对应的数据, 从该表可以初步看 到抑水峰的效果.

表 1 定域谱利抑水峰定域谱之比较

\begin{tabular}{lcccccccc}
\hline & $\mathrm{H}_{2} \mathrm{O}$ & \multicolumn{4}{c}{$-\mathrm{CH}_{2}-$} & \multicolumn{4}{c}{$-\mathrm{CH}_{3}$} \\
\hline & 2.7 & 14.7 & 47.9 & 49.9 & 17.0 & 55.7 & 104.2 & 48.1 \\
抑制水峰 MRS & 100 & 0.72 & 2.34 & 2.61 & 0.92 & 2.06 & 3.81 & 1.73 \\
MRS & & 100 &
\end{tabular}

以一 $\mathrm{CH}_{3}$ 信号峰的中间谱线为基准, 水峰抑制了 1000 倍, 且 $-\mathrm{CH}_{2}-$ 与- $\mathrm{CH}_{3}$ 信号强度 的积分比为 $1: 1.60$, 接近 $2: 3$.

这一结果为我们开展下一步的工作创造了条件. 


\section{参考文献}

1 Callaghan P T. Principles of Nuclear Magnetic Resonance Microscopy, 1st ed. Oxford: Clarendon Press, 1991

2 Blumich B, Kuhn W. Magnetic Resonance Microscopy, 1st ed. Weinheim: VCH Press, 1992

3 Wehrli F W. The origins and future of nuclear magnetic resonance imaging. Physics Today, 1992, (6): $34 \sim 42$

4 Alper J. Biomedicine in the age of imaging. Science, 1993, 261:554 559

5 Frahm J, Merboldt K D, Hanicke W. Localized proton spectroscopy using stimulated echoes. J Magn Reson, 1987, 72: $502 \sim 508$

6 Mao X A, Ye C H. Phase-shift presaturation in one- and two-dimension NMR experiment. Chem Phys Lett, 1994, $227: 645 \sim 650$ 